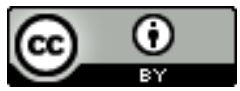

Esta obra está sob o direito de Licença Creative Commons Atribuição 4.0 Internacional.

\title{
DISCIPLINA POSITIVA: UM MÉTODO INOVADOR DE EDUCAR COM FIRMEZA E GENTILEZA
}

\author{
Cleidejane Soares de Barros ${ }^{1}$ \\ Betijane Soares de Barros ${ }^{2}$ \\ Eliane Reis Neves da Silva ${ }^{3}$
}

\section{RESUMO}

A disciplina positiva, por ser um método inovador de educar, sem a utilização do sistema punitivo ou de recompensa, tem atraído o olhar dos educadores. Na presente pesquisa, a análise é da disciplina positiva e seu impacto na educação, a fim de revelar a importância dessa temática e sua incidência na produção de melhorias no sistema Ensino-Aprendizagem para educação. A pesquisa analisou produções científicas publicadas entre 2015 e 2020, nos sites: BVS, Scielo, Periódicos da Capes, Wiley e Science Direct. O objetivo deste trabalho foi caracterizar a disciplina positiva como um método de educar para formar cidadãos conscientes, com controle emocional e com autoestima elevada. Trata-se de uma revisão sistemática. Utilizando os descritores estruturados no DeCS e MeSH. O período de coleta dos dados correu no mês de maio de 2020. Foi utilizado como critério de inclusão artigos científicos relacionados ao tema e, como critérios de exclusão, artigos científicos que não contemplam a temática sobre disciplina positiva. Deste modo, conclui-se que a Disciplina Positiva é um método essencial e inovador na educação de crianças, seja no ambiente escolar ou domiciliar.

PALAVRAS-CHAVE: Disciplina positiva. Método. Educação. Educar.

\footnotetext{
${ }^{1}$ dr.csbarros@hotmal.com.

2 bj-sb@hotmal.com.

3 elianereis.@uol.com.br
} 


\section{INTRODUÇÃO}

A disciplina positiva traz uma visão inovadora sobre educação para pais e professores, ajudando os adultos a descobrir uma solução respeitosa, que não seja punitivo nem permissivo. A disciplina positiva apresenta ferramentas que são simultaneamente gentis e firmes e que buscam ensinar valiosas habilidades sociais, em situações de rotina, desafiadoras ou não (ALARCÓN; CAYCHO RODRÍGUEZ, 2015, p. 59-69).

A proposta envolve uma mudança de paradigma, migrando de uma cultura autoritária e ancorada no medo para um formato de convivência colaborativa, onde todos são ouvidos, respeitados e desenvolvem um senso de comunidade. Assim, tem-se como objetivo caracterizar a disciplina positiva como um método de educar para formar cidadãos conscientes, com controle emocional e com autoestima elevada (ARIAS CHACÓN, 2018, p. 157).

Na prática, há a desistência em manter posturas punitivas como castigos, gritos ou o cantinho do pensamento. Há a desistência também da lógica do oferecimento de recompensas para obtenção da mudança de comportamento das crianças (ALTAFIM; RODRIGUES, 2015, p. 257-262).

Um ponto importante e primordial para o sucesso da disciplina positiva é o estabelecimento de limites. Os limites são basilares e estruturantes para a personalidade que está se formando. A criança precisa saber que existe pessoas com as quais ela pode confiar e que será acolhida por elas, sem ameaças ou humilhação, esse cenário proporcionará a criança autonomia para expor o que sente e a pedir ajuda quando sentir necessidade (FERREIRA; ANDRADE, 2017, p. 245-252).

A falta ou a disponibilidade de tempo tem sido o desafio principal para as famílias, principalmente, se anexar a disponibilidade de tempo a qualidade desse tempo disponível para o convívio com os filhos. A rotina diária com longas jornadas de trabalho, que muitas vezes se estende até em casa, o cansaço físico e mental decorrente dessa rotina e a necessidade de dedicar parte do tempo as redes sociais, internet e as telas em geral, são fatores que reduzem significativamente $\mathrm{o}$ espaço da convivência familiar, tendo como consequência mitigados momentos de brincadeiras e diálogo (MARIA, 2016, p. 277).

Pais e professores têm problemas com o conceito de ser gentil e firme na medida certa, pois pensam que não existe meio termo, “ou é um ou é o outro". Na prática, encontrar o caminho da gentileza e da não-violência é um desafio importante, já que, muitas pessoas sofreram com métodos educativos impositivos e violentos, baseados no conceito de obediência sem discussão. Além disso, muitas vezes os sentimentos negativos como a 
culpa, frustração e vergonha por sentirem-se falhando na missão de educar fazem com que os pais demorem a buscar apoio profissional, o que pode levar ao estado de exaustão e desequilíbrio de todo o sistema familiar (ARIAS CHACÓN, 2018, p. 157).

\section{MÉTODOLOGIA}

Trata-se de uma revisão sistemática, que seguiu as seguintes etapas (ver Quadro 1): definição do tema; seleção da pergunta norteadora e escolha da estratégia de busca; descritores e bases de dados mais eficazes no levantamento das publicações; escolha dos critérios de inclusão e exclusão; identificação dos estudos pré-selecionados e selecionados por meio da leitura dos agentes indexadores das publicações, como resumos, palavras-chave e títulos, bem
A disciplina positiva por ser um método inovador que possui impacto no sistema educacional, pois a sua incidência produz melhorias e avanço no ensinoaprendizagem no só no ambiente escolar, como também, na educação domiciliar (NELSEN, 2015).

como a organização dos estudos préselecionados e a identificação dos estudos selecionados; categorização dos estudos selecionados, com a elaboração e o uso da matriz de síntese, além da análise das informações; a formação de uma biblioteca individual e a avaliação crítica dos estudos selecionados; análise, interpretação e discussão dos resultados e a apresentação da revisão em formato de artigo, o qual contempla as propostas para estudos futuros.

Quadro 1 - Detalhamento das etapas da Revisão Sistemática.

\begin{tabular}{|c|c|c|}
\hline ETAPA & $\begin{array}{c}\text { TÓPICOS } \\
\text { DE CADA } \\
\text { ETAPA }\end{array}$ & DETALHAMENTO DE CADA TÓPICO \\
\hline \multirow[t]{6}{*}{$1^{\mathrm{a}}$} & Tema & $\begin{array}{l}\text { Disciplina Positiva: um método inovador de educar com firmeza e } \\
\text { gentileza. }\end{array}$ \\
\hline & $\begin{array}{c}\text { Pergunta } \\
\text { norteadora }\end{array}$ & $\begin{array}{l}\text { Como a disciplina positiva pode contribuir para formação de } \\
\text { cidadãos conscientes, com controle emocional e com autoestima } \\
\text { elevada? }\end{array}$ \\
\hline & $\begin{array}{l}\text { Objetivo } \\
\text { geral }\end{array}$ & $\begin{array}{l}\text { Caracterizar a disciplina positiva como um método de educar para } \\
\text { formar cidadãos conscientes, com controle emocional e com } \\
\text { autoestima elevada. }\end{array}$ \\
\hline & $\begin{array}{l}\text { Estratégias } \\
\text { de busca }\end{array}$ & $\begin{array}{l}\text { 1. Cruzamento de descritores por meio do operador booleano } \\
\text { AND; } \\
\text { 2. Uso de descritores estruturados (codificação) no DECS ou } \\
\text { MESH; } \\
\text { 3. Uso de metadados (filtros). }\end{array}$ \\
\hline & \multirow{2}{*}{$\begin{array}{c}\text { Bancos de } \\
\text { terminologias }\end{array}$} & Banco \\
\hline & & http://decs.bvs.br/ \\
\hline
\end{tabular}




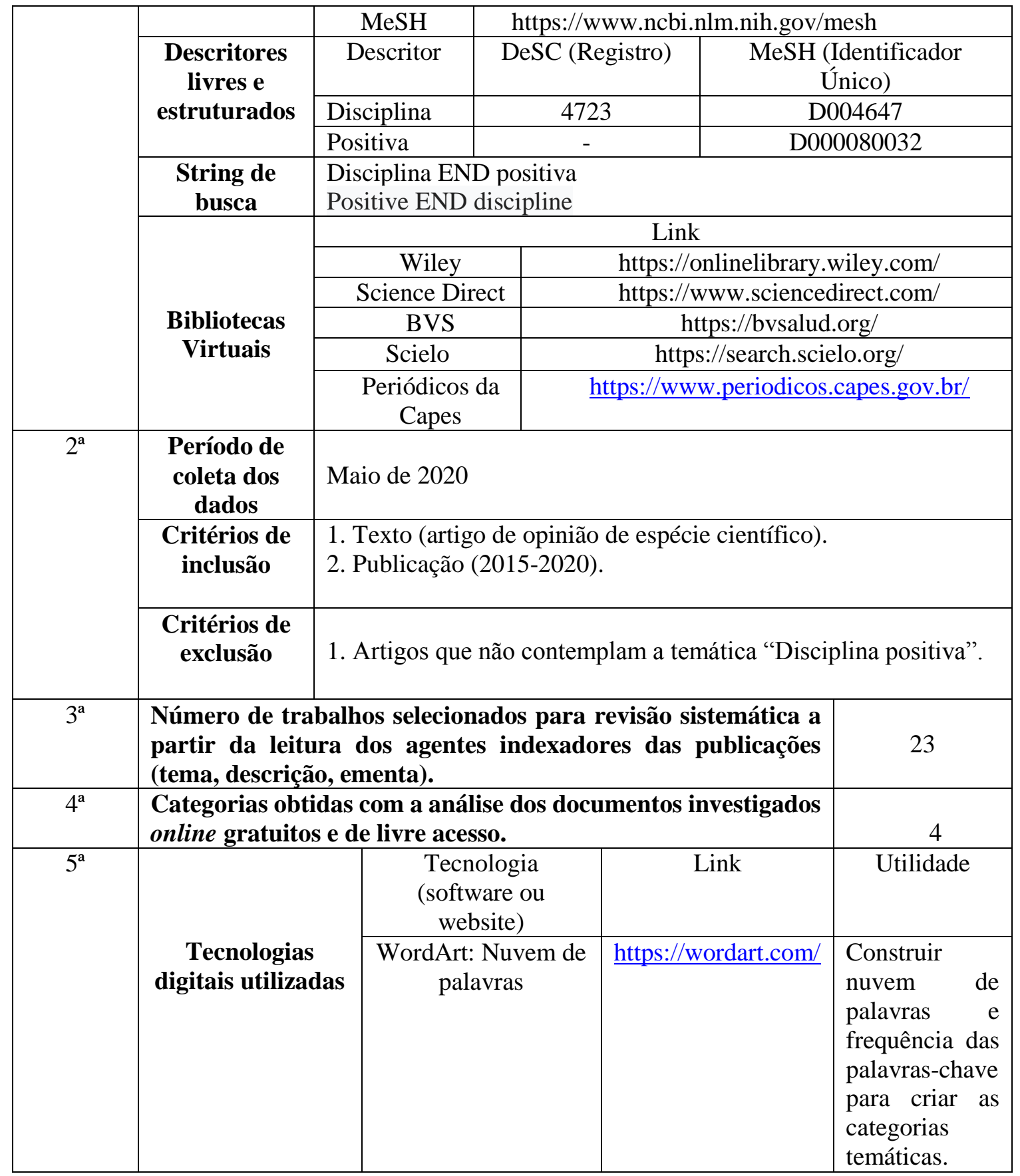

Fonte: Autoria própria.

\section{RESULTADOS}

Foram detectadas 258.351

publicações científicas nos bancos de dados, das quais 60.450 eram artigos disponíveis após o uso dos filtros, desses foram feitos 23 downloads, que obedeceram aos critérios de inclusão, sendo submetidos às etapas da revisão sistemática. 
Quadro 2 - Corresponde ao total de documentos disponíveis nas Plataforma BVS, Scielo e Periódicos da Capes, obtidos por string de busca.

\begin{tabular}{|c|c|c|c|c|}
\hline String de busca & $\begin{array}{l}\text { Bases de dados } \\
\text { Plataforma }\end{array}$ & $\begin{array}{c}\text { Total de } \\
\text { publicações } \\
\text { sem o filtro }\end{array}$ & $\begin{array}{l}\text { Publicações } \\
\text { disponíveis } \\
\text { após aplicar } \\
\text { os filtros }\end{array}$ & $\begin{array}{c}\text { Publicações } \\
\text { aproveitadas na } \\
\text { Revisão } \\
\text { Sistemática }\end{array}$ \\
\hline \multirow[t]{2}{*}{ Disciplina positiva } & Wiley & 138.461 & 31.798 & 6 \\
\hline & Science Direct & 114.906 & 26.812 & 2 \\
\hline \multirow{2}{*}{$\begin{array}{l}\text { Disciplina } \\
\text { positiva }\end{array}$} & BVS & 113 & 35 & 3 \\
\hline & Scielo & 98 & 35 & 10 \\
\hline \multirow{2}{*}{$\begin{array}{l}\text { Positive } \\
\text { discipline }\end{array}$} & $\begin{array}{c}\text { Periódicos da } \\
\text { Capes }\end{array}$ & 4.773 & 1.770 & 2 \\
\hline & TOTAL & 258.351 & 60.450 & 23 \\
\hline
\end{tabular}

Fonte: Elaborada pelos autores.

Quadro 3 - Descrição dos documentos (artigos) de acordo com os critérios de inclusão.

\begin{tabular}{|c|c|c|c|c|}
\hline ARTIGO & AUTOR(A) & TEMA & $\begin{array}{c}\text { ANO DA } \\
\text { PUBLICAÇÃO }\end{array}$ & CONCLUSÃO \\
\hline 1 & $\begin{array}{l}\text { Elif Dede } \\
\text { Yildirim } \\
\text { aipaul } \\
\text { LRoopnarine }\end{array}$ & 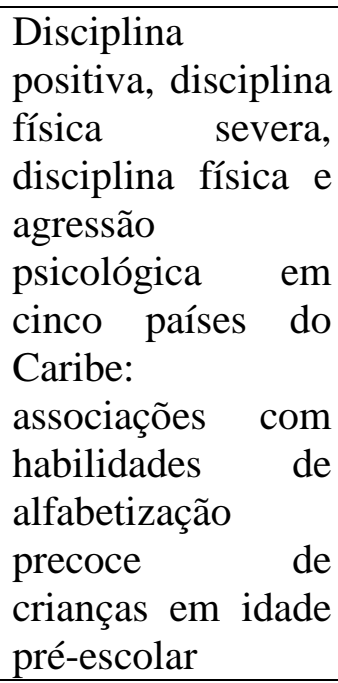 & 2019 & $\begin{array}{lr}\text { As conclusões são } \\
\text { discutidas com respeito às } \\
\text { consequências negativas } \\
\text { de práticas disciplinares } \\
\text { severas sobre as } \\
\text { habilidades } \\
\text { alfabetização de crianças } \\
\text { em idade pré-escolar no } \\
\text { mundo } \\
\text { desenvolvimento. }\end{array}$ \\
\hline 2 & $\begin{array}{ll}\text { Robert } & \text { E. } \\
\text { Larzelere } & \\
\text { Brett } & \text { R. } \\
\text { Kuhn } & \end{array}$ & Disciplina dos Pais & 2016 & $\begin{array}{l}\text { A medida que os pais se } \\
\text { tornam ainda mais } \\
\text { confusos quanto às } \\
\text { maneiras de impor } \\
\text { disciplina aos seus filhos, } \\
\text { as crianças, igualmente, se } \\
\text { confundirão quanto ao que } \\
\text { se espera da parte delas. }\end{array}$ \\
\hline 3 & $\begin{array}{ll}\text { Alex } & \text { M. } \\
\text { Wood } & \\
\text { Judith } & \\
\text { Johnson } & \end{array}$ & $\begin{array}{l}\text { Psicologia Clínica } \\
\text { Positiva }\end{array}$ & 2016 & $\begin{array}{l}\text { Entre os aspectos que } \\
\text { podem surgir em terapia } \\
\text { estão a mudança de } \\
\text { relação com as famílias de } \\
\text { origem, o aumento de } \\
\text { interesses ou busca de } \\
\text { novas possibilidades } \\
\text { profissionais dos cônjuges }\end{array}$ \\
\hline
\end{tabular}




\begin{tabular}{|c|c|c|c|c|}
\hline & & & & $\begin{array}{l}\text { e a coparentalidade em si } \\
\text { mesma. }\end{array}$ \\
\hline 4 & $\begin{array}{l}\text { Brian G. } \\
\text { Pauwels }\end{array}$ & $\begin{array}{l}\text { O desconfortável - e } \\
\text { necessário - papel do } \\
\text { negativo na } \\
\text { psicologia positiva }\end{array}$ & 2015 & $\begin{array}{l}\text { A psicologia positiva na } \\
\text { prática, promovendo o } \\
\text { florescimento humano no } \\
\text { trabalho, saúde, educação } \\
\text { e vida cotidiana. }\end{array}$ \\
\hline 5 & $\begin{array}{l}\text { Stephen } \\
\text { Joseph }\end{array}$ & 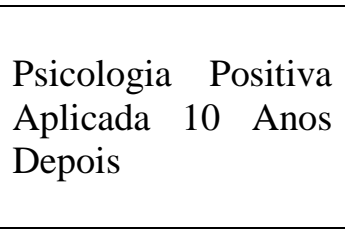 & 2015 & $\begin{array}{l}\text { A psicologia positiva na } \\
\text { prática, promovendo o } \\
\text { florescimento humano no } \\
\text { trabalho, saúde, educação } \\
\text { e vida cotidiana. }\end{array}$ \\
\hline 6 & $\begin{array}{l}\text { Stephen } \\
\text { Joseph }\end{array}$ & $\begin{array}{l}\mathrm{O} \text { futuro da } \\
\text { psicologia positiva } \\
\text { na prática }\end{array}$ & 2015 & $\begin{array}{l}\text { A psicologia positiva na } \\
\text { prática, promovendo o } \\
\text { florescimento humano no } \\
\text { trabalho, saúde, educação } \\
\text { e vida cotidiana. }\end{array}$ \\
\hline 7 & $\begin{array}{l}\text { Celal Teyyar } \\
\text { Ugurlua } \\
\text { Kadir } \\
\text { Beycioglu } \\
\text { Yasar } \\
\text { Kondakc1 } \\
\text { Mehmet } \\
\text { Sincar } \\
\text { M.Cevat } \\
\text { Y1ldırıme } \\
\text { Niyazi Ozer } \\
\text { Aziz Oncel }\end{array}$ & $\begin{array}{l}\text { The Views Of } \\
\text { Teachers Towards } \\
\text { Perception } \\
\text { Discipline In } \\
\text { Schools }\end{array}$ & 2015 & $\begin{array}{l}\text { In our study where we } \\
\text { have taken a look at } \\
\text { teachers' perceptions of } \\
\text { the perception } \\
\text { discipline at } \\
\text { schools: The overall } \\
\text { influence of the perception } \\
\text { of discipline on teachers, } \\
\text { our teachers' general } \\
\text { views on student } \\
\text { discipline, the differences } \\
\text { of the disciplined and } \\
\text { undisciplined students } \\
\text { have been put forward. It } \\
\text { has been understood that } \\
\text { among our teachers' } \\
\text { views on the perception of } \\
\text { discipline, the categories } \\
\text { of order, rules, } \\
\text { volunteering } \\
\text { autonomy have been of the } \\
\text { utmost priority. }\end{array}$ \\
\hline 8 & $\begin{array}{l}\text { Aleksandrs } \\
\text { Gorbunovsa } \\
\text { Atis } \\
\text { Kapenieks } \\
\text { Sarma } \\
\text { Cakula }\end{array}$ & $\begin{array}{l}\text { Self-discipline as a } \\
\text { key indicator to } \\
\text { improve learning } \\
\text { outcomes } \\
\text { elearning } \\
\text { environment }\end{array}$ & 2016 & $\begin{array}{l}\text { The authors prove this } \\
\text { statement by data analysis } \\
\text { of learner activity levels } \\
\text { within } \\
\text { collaborative e-learning } \\
\text { environment and achieved } \\
\text { appropriate competence } \\
\text { levels. Self-discipline and } \\
\text { motivation issues are also } \\
\text { discussed. }\end{array}$ \\
\hline 9 & $\begin{array}{l}\text { Victor Silva } \\
\text { Ferreira } \\
\text { Márcia } \\
\text { Siqueira } \\
\text { Andrade }\end{array}$ & $\begin{array}{l}\text { A Relação } \\
\text { Professor-Aluno no } \\
\text { Ensino Médio: } \\
\text { Percepção do } \\
\text { Professor de Escola } \\
\text { Pública }\end{array}$ & 2017 & $\begin{array}{l}\text { Ao correlacionar a } \\
\text { variável de desempenho } \\
\text { acadêmico com os } \\
\text { indicadores de afinidade e } \\
\text { conflito verificou se }\end{array}$ \\
\hline
\end{tabular}




\begin{tabular}{|c|c|c|c|c|}
\hline & & & & $\begin{array}{l}\text { que existe correlação } \\
\text { positiva fraca entre o } \\
\text { indicador de conflito e o } \\
\text { desempenho acadêmico da } \\
\text { disciplina Filosofia. } \\
\text { Contudo, na disciplina de } \\
\text { Geografia, existe também } \\
\text { uma correlação positiva } \\
\text { fraca, mas, com o } \\
\text { indicador de afinidade. }\end{array}$ \\
\hline 10 & $\begin{array}{l}\text { Sinara } \\
\text { Pereira de } \\
\text { Souza } \\
\text { Paulo } \\
\text { Rogerio } \\
\text { Barbosa do } \\
\text { Nascimento } \\
\text { Paulo Evaldo } \\
\text { Fensterseifer }\end{array}$ & $\begin{array}{l}\text { Atuação docente em } \\
\text { Educação Física } \\
\text { escolar: } \\
\text { entre investimento e } \\
\text { desinvestimento } \\
\text { pedagógico }\end{array}$ & & $\begin{array}{l}\text { O estudo identificou que } \\
\text { certos aspectos da cultura } \\
\text { escolar tensionam a } \\
\text { manutenção de } \\
\text { um perfil de investimento } \\
\text { pedagógico. }\end{array}$ \\
\hline 11 & $\begin{array}{l}\text { Elisa Rachel } \\
\text { Pisani } \\
\text { Altafim } \\
\text { Olga Maria } \\
\text { Piazentin } \\
\text { Rolim } \\
\text { Rodrigues }\end{array}$ & $\begin{array}{l}\text { Práticas Educativas } \\
\text { Maternas o Primeiro } \\
\text { Ano de Vida }\end{array}$ & 2015 & $\begin{array}{l}\text { Os resultados revelaram } \\
\text { que as mães utilizam-se } \\
\text { com frequência da } \\
\text { prática parental positiva } \\
\text { Monitoria Positiva, no } \\
\text { entanto as práticas } \\
\text { negativas, também são } \\
\text { presentes } \\
\text { no repertório das } \\
\text { participantes, } \\
\text { principalmente a prática } \\
\text { Disciplina Relaxada. }\end{array}$ \\
\hline 12 & $\begin{array}{l}\text { Reynaldo } \\
\text { Alarcón } \\
\text { Tomás } \\
\text { Caycho } \\
\text { Rodríguez }\end{array}$ & $\begin{array}{l}\text { Relaciones entre } \\
\text { gratitud y felicidad } \\
\text { en estudiantes } \\
\text { universitarios de } \\
\text { lima } \\
\text { metropolitana }\end{array}$ & 2015 & $\begin{array}{l}\text { El agradecer el beneficio } \\
\text { recibido y la satisfacción } \\
\text { que esto conlleva tiende a } \\
\text { estar relacionado con } \\
\text { actitudes y experiencias } \\
\text { positivas hacia la vida, } \\
\text { satisfacción por lo que se } \\
\text { ha alcanzado y la } \\
\text { autosuficiencia } \\
\text { tranquilidad emocional. } \\
\text { Cualidad sentimental se } \\
\text { relaciona positiva y } \\
\text { significativamente con la } \\
\text { felicidad (r =.218, }<\text {.05) } \\
\text { y con satisfacción con la } \\
\text { vida. Entre la gratitud y la } \\
\text { felicidad no se observan } \\
\text { diferencias } \\
\text { estadísticamente } \\
\text { significativas } \\
\text { varones y mujeres. }\end{array}$ \\
\hline 13 & $\begin{array}{l}\text { Luis Gerardo } \\
\text { Meza } \\
\text { Cascante }\end{array}$ & $\begin{array}{l}\text { La actitud del } \\
\text { personal docente de } \\
\text { matemática hacia el }\end{array}$ & 2015 & $\begin{array}{l}\text { Los hallazgos sugieren } \\
\text { una actitud positiva de los } \\
\text { docentes hacia la }\end{array}$ \\
\hline
\end{tabular}




\begin{tabular}{|c|c|c|c|c|}
\hline & $\begin{array}{l}\text { Zuleyka } \\
\text { Suárez } \\
\text { Valdés- } \\
\text { Ayala } \\
\text { Sandra } \\
\text { Schmidt } \\
\text { Quesada }\end{array}$ & $\begin{array}{lr}\text { aprendizaje } & \\
\text { cooperativo y los } \\
\text { elementos } \\
\text { institucionales que } \\
\text { favorecen } \\
\text { dificultan el empleo } \\
\text { de esa metodología } \\
\text { didáctica }\end{array}$ & & $\begin{array}{l}\text { integración del trabajo } \\
\text { cooperativo } \\
\text { estrategia didáctica para } \\
\text { promover aprendizajes de } \\
\text { la matemática y acia el } \\
\text { papel desempenado por } \\
\text { los directores de los } \\
\text { centros educativos en la } \\
\text { adopción de innovaciones } \\
\text { educativas. }\end{array}$ \\
\hline 14 & $\begin{array}{l}\text { Ana Maria } \\
\text { Santos Gouw } \\
\text { Nelio Marco } \\
\text { Vincenzo } \\
\text { Bizzo }\end{array}$ & $\begin{array}{l}\text { A percepção dos } \\
\text { jovens brasileiros } \\
\text { sobre suas aulas de } \\
\text { Ciências }\end{array}$ & 2016 & $\begin{array}{l}\text { Há uma atitude geral } \\
\text { positiva em relação à } \\
\text { disciplina, tanto no que se } \\
\text { refere à sua importância } \\
\text { como à sua utilidade. }\end{array}$ \\
\hline 15 & $\begin{array}{l}\text { Maria de } \\
\text { Fátima } \\
\text { Minetto } \\
\text { Suzane } \\
\text { Schmidlin } \\
\text { Löhr }\end{array}$ & $\begin{array}{l}\text { Crenças e práticas } \\
\text { educativas de mães } \\
\text { de crianças com } \\
\text { desenvolvimento } \\
\text { atípico }\end{array}$ & 2016 & $\begin{array}{l}\mathrm{Na} \text { análise de pares de } \\
\text { dimensões do E-CPPC foi } \\
\text { percebido que somente no } \\
\text { par de dimensões } \\
\text { Apresentação- } \\
\text { Responsividade/vínculo } \\
\text { houve diferença entre os } \\
\text { grupos, sendo positiva e } \\
\text { com significância } \\
\text { estatística nas crianças } \\
\text { com Síndrome de Down e } \\
\text { não apresentando relação } \\
\text { significativa } \\
\text { no outro grupo. }\end{array}$ \\
\hline 16 & $\begin{array}{l}\text { Moysés } \\
\text { Kuhlmann Jr. }\end{array}$ & $\begin{array}{l}\text { Parque Infantil: a } \\
\text { singularidade e seus } \\
\text { componentes }\end{array}$ & 2019 & $\begin{array}{l}\text { A interpretação se } \\
\text { distancia de atribuir } \\
\text { valor às instituições, seja } \\
\text { de forma positiva ou } \\
\text { negativa. Considera-se } \\
\text { que não basta adjetivá-las } \\
\text { como promotoras da } \\
\text { cultura e da cidadania, ou } \\
\text { ao contrário, do controle e } \\
\text { da disciplina, pois ambas } \\
\text { as dimensões podem ser } \\
\text { identificadas nos } \\
\text { elementos presentes nas } \\
\text { propostas. }\end{array}$ \\
\hline 17 & $\begin{array}{l}\text { João Paulo } \\
\text { Koltermann } \\
\text { Carolina } \\
\text { Duarte de } \\
\text { Souza } \\
\text { Rovana } \\
\text { Kinas Bueno } \\
\text { Larissa } \\
\text { Paraventi } \\
\text { Mauro Luis } \\
\text { Vieira } \\
\end{array}$ & $\begin{array}{l}\text { Openness to the } \\
\text { World by Fathers } \\
\text { and Mothers of } \\
\text { Preschoolers in } \\
\text { Two-parent Families }\end{array}$ & 2019 & $\begin{array}{l}\text { Pelos benefícios da AM } \\
\text { para o desenvolvimento } \\
\text { infantil, sugere- se incluí- } \\
\text { la em Políticas Públicas } \\
\text { que promovam } \\
\text { parentalidade positiva. }\end{array}$ \\
\hline
\end{tabular}

Fonte: Plataformas: BVS, Scielo, Periódicos da Capes, Wiley e Science Direct, 2020. 


\begin{tabular}{|c|c|c|c|c|}
\hline 18 & $\begin{array}{l}\text { Sílvia } \\
\text { Cristina } \\
\text { Marques } \\
\text { Nunes } \\
\text { PricinoteI } \\
\text { Artur } \\
\text { Lorenzo Sena } \\
\text { GomesI } \\
\text { Alberto } \\
\text { Monteiro } \\
\text { FilhoI Bruno } \\
\text { Leonardo } \\
\text { Wadson } \\
\text { SilvaI } \\
\text { Reinaldo } \\
\text { Elias } \\
\text { Souza de } \\
\text { JuniorI } \\
\text { Denise } \\
\text { Milioli } \\
\text { FerreiraI } \\
\text { Maria do } \\
\text { Rosário } \\
\text { Ferraz } \\
\text { RobertiI } \\
\text { Marcos Rassi } \\
\text { Fernandes } \\
\end{array}$ & $\begin{array}{l}\text { Percepção Discente } \\
\text { sobre o Ambiente } \\
\text { Educacional da } \\
\text { Disciplina de } \\
\text { Semiologia Médica }\end{array}$ & 2020 & $\begin{array}{l}\text { O ambiente educacional } \\
\text { das disciplinas de } \\
\text { Semiologia I e II da } \\
\text { Faculdade de } \\
\text { Medicina da UFG criado } \\
\text { pelas r inovações } \\
\text { metodológicas } \quad \text { foi } \\
\text { avaliado positivamente } \\
\text { pelos ros discentes } \\
\text { participantes, r com } \\
\text { destaque para o domínio } \\
\text { percepção dos docentes. }\end{array}$ \\
\hline 19 & $\begin{array}{l}\text { Himmbler } \\
\text { Olivares } \\
\text { David Silva } \\
\text { Paloma } \\
\text { Opazo } \\
\text { Tomás } \\
\text { Arellano } \\
\text { Carlos } \\
\text { Cornejo }\end{array}$ & $\begin{array}{l}\text { La urdiembre en la } \\
\text { enseñanza: } \\
\text { expresiones } \\
\text { articuladoras de } \\
\text { contenido en la } \\
\text { interacción profesor- } \\
\text { estudiante }\end{array}$ & 2020 & $\begin{array}{l}\text { Los resultados muestran } \\
\text { que las expresiones } \\
\text { articuladoras, en particular } \\
\text { las de carácter local, } \\
\text { correlacionan de } \\
\text { forma positiva, pero con } \\
\text { un efecto reducido, con } \\
\text { distintas dimensiones del } \\
\text { desempeño docente, tales } \\
\text { como la capacidad del } \\
\text { profesor de dar estructura } \\
\text { a la clase o la promoción } \\
\text { de la interacción } \\
\text { pedagógica. articuladoras } \\
\text { expresiones articas } \\
\text { corresponderían a un } \\
\text { recurso pedagógico } \\
\text { importante del docente } \\
\text { para el aprendizaje, en } \\
\text { tanto facilitan la } \\
\text { enseñanza del lenguaje } \\
\text { técnico de cada disciplina. }\end{array}$ \\
\hline 20 & $\begin{array}{l}\text { Johel } \\
\text { Furguerle } \\
\text { Rangel } \\
\text { José Pacheco } \\
\text { Barrios }\end{array}$ & $\begin{array}{l}\text { Apreciaciones sobre } \\
\text { la quinta disciplina } \\
\text { en la construcción } \\
\text { deorganizaciones } \\
\text { educativas } \\
\text { inteligentes }\end{array}$ & 2018 & $\begin{array}{l}\text { Se concluye que el grupo } \\
\text { docente encuestado tiene } \\
\text { actitud positiva por el } \\
\text { pensamiento sistémico de } \\
\text { la quinta disciplina, por ser } \\
\text { la integradora de las }\end{array}$ \\
\hline
\end{tabular}




\begin{tabular}{|c|c|c|c|c|}
\hline & $\begin{array}{l}\text { Gilberto } \\
\text { Bastidas } \\
\text { Pacheco }\end{array}$ & & & $\begin{array}{ll}\text { demás doctrinas } & \text { o } \\
\text { postulados. }\end{array}$ \\
\hline 21 & $\begin{array}{l}\text { Ángel } \\
\text { Alberto } \\
\text { Valdés } \\
\text { Cuervo } \\
\text { Ernesto } \\
\text { Alonso } \\
\text { Carlos } \\
\text { Martínez } \\
\text { Jesús Tánori } \\
\text { Quintana } \\
\text { Esthela } \\
\text { Jacqueline } \\
\text { Madrid } \\
\text { López }\end{array}$ & $\begin{array}{l}\text { Relación Entre } \\
\text { Funcionamiento } \\
\text { Familiar, Emociones } \\
\text { Morales Y Violencia } \\
\text { Entre Estudiantes de } \\
\text { Primaria }\end{array}$ & 2016 & $\begin{array}{l}\text { Se concluye que las } \\
\text { características } \\
\text { funcionamiento familiar } \\
\text { afectan el desarrollo de } \\
\text { emociones morales, tales } \\
\text { como la empatía y la } \\
\text { vergüenza, las cuales se } \\
\text { asocian con una menor } \\
\text { frecuencia de agresión } \\
\text { entre estudiantes. }\end{array}$ \\
\hline 22 & $\begin{array}{l}\text { Marisa } \\
\text { Carvalho } \\
\text { Paula AlĂo } \\
\text { Joaquim } \\
\text { MagalhĂes }\end{array}$ & $\begin{array}{l}\text { Da Indisciplina ao } \\
\text { Clima de Escola: A } \\
\text { Voz dos Alunos }\end{array}$ & 2017 & $\begin{array}{l}\text { Consideramos que as } \\
\text { assembleias de alunos } \\
\text { constituem ruma } \\
\text { abordagem promissora na } \\
\text { promoĆĂo de um clima } \\
\text { de escola positivo, } \\
\text { participado e } \\
\text { democratico. }\end{array}$ \\
\hline 23 & $\begin{array}{l}\text { Guiselle } \\
\text { Arias Chacón } \\
\text { Vivian } \\
\text { Carvajal } \\
\text { Jiménez } \\
\text { Luis Elías } \\
\text { Cascante } \\
\text { Arrieta } \\
\text { Maricela } \\
\text { Corrales } \\
\text { Naranjo } \\
\text { Mónica } \\
\text { Quesada } \\
\text { Mora Juan } \\
\text { Carlos } \\
\text { Zamora } \\
\text { Montero }\end{array}$ & $\begin{array}{l}\text { Contribuciones de la } \\
\text { teoría disciplina } \\
\text { positiva: Una } \\
\text { experiencia en la } \\
\text { comunidad rural La } \\
\text { Maravilla, San Vito } \\
\text { de Coto Brus }\end{array}$ & 2018 & $\begin{array}{l}\text { Para abordar el tema, se } \\
\text { estudiaron textos e } \\
\text { investigaciones que dan } \\
\text { cuenta de la efectividad de } \\
\text { la disciplina positiva como } \\
\text { alternativa a las formas de } \\
\text { crianza tradicionales, se } \\
\text { entrevistó a personas } \\
\text { expertas en el tema y el } \\
\text { equipo investigador } \\
\text { recibió capacitación de } \\
\text { distintas la } \\
\text { organizaciones.Finalment } \\
\text { e, se desarrollan talleres } \\
\text { educativos con la } \\
\text { comunidad involucrada y } \\
\text { se generó un compendio } \\
\text { de estrategias para apoyar } \\
\text { el uso de la disciplina } \\
\text { positiva en los hogares } \\
\text { rurales. }\end{array}$ \\
\hline
\end{tabular}

O corpo textual foi analisado por meio da frequência de palavras, que originou a nuvem de palavras (Figura 1) criada na Plataforma online WordArt. Esta ferramenta agrupa e organiza graficamente as palavras-chave evidenciando as mais frequentes. Por meio da Figura 1, foi possível observar que as palavras em 
evidência na nuvem pertencem as categorias desenvolvidas a partir da análise de conteúdo de Bardin. Todas as categorias derivam da sua frequência (Tabela 1), que diz respeito ao seu quadro referencial. Em consonância ao objetivo deste trabalho, optou-se por descrever as palavras que apresentaram frequência total no texto e, a partir de seus sentidos nos campos textuais, tinham maior relevância para as representações sociais sobre gênero, como apresentado na Quadro 2.

Figura 1 - Nuvem de Palavras.

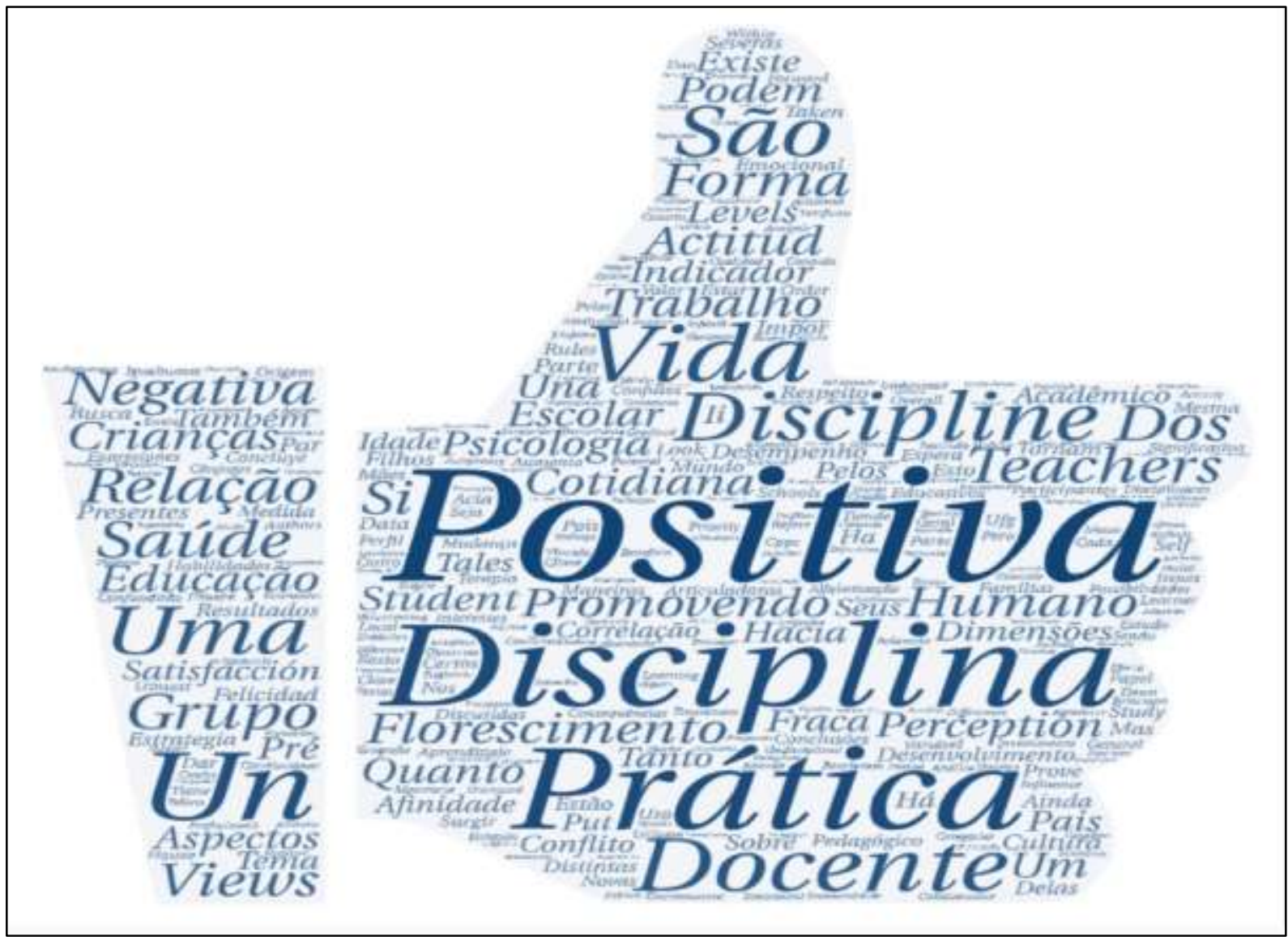

Fonte: Elaborada pelos autores.

Tabela 1 - Frequência das palavras presentes nos textos publicados pelos artigos nas Plataformas: BVS, Scielo e Periódicos da Capes.

\begin{tabular}{|c|c|c|}
\hline PALAVRAS & FREQUÊNCIA & CATEGORIAS \\
\hline Disciplina & 11 & \multirow{3}{*}{ Disciplina Positiva na Prática } \\
\hline Positiva & 18 & \\
\hline Prática & 7 & \\
\hline Florescimento & 3 & \multirow{3}{*}{$\begin{array}{l}\text { O Florescimento da Disciplina } \\
\text { Positiva }\end{array}$} \\
\hline Disciplina & 11 & \\
\hline Positiva & 18 & \\
\hline Implementação & 1 & \multirow{3}{*}{$\begin{array}{l}\text { Implementação da Disciplina } \\
\text { Positiva na vida Cotidiana }\end{array}$} \\
\hline Disciplina & 11 & \\
\hline Positiva & 18 & \\
\hline
\end{tabular}




\begin{tabular}{l|l|l}
\hline Vida & 1 & \multirow{2}{*}{} \\
\hline Cotidiano & 1 & \\
\hline
\end{tabular}

Fonte: Elaborada pelos autores.

\section{DISCUSSÕES}

A disciplina positiva utiliza $\mathrm{o}$ emocional aliado ao respeito, ou seja, funda-se no respeito mútuo e na cooperação por meio do encorajamento e da compreensão, sendo à firmeza a base de tudo. A disciplina positiva consistirá no alicerce para o desenvolvimento de competências essenciais para a vida e para construir pessoas autoconfiantes, seguras e capazes de tomar decisões sozinhas (NELSEN, 2015).

No entanto, pais e profissionais da educação sentem muita dificuldade em despojassem dos métodos tradicionais de disciplinar com a utilização do autoritarismo e castigos. Assim, é necessário treinamento, capacitação e paciência para os mesmos, relacionados a disciplina positiva.

Seguem abaixo, as categorias temáticas elaboradas a partir da revisão sistemática integrativa.

\section{Disciplina positiva na prática}

A disciplina positiva traz uma visão de respeito e empatia pelas emoções do outro e também o convite para uma forma colaborativa de solução para as questões do dia a dia. Em situações de rotina, desafiadoras ou não Nelsen (2015, p. 62). A proposta envolve uma mudança de paradigma: migrando de uma cultura autoritária e ancorada no medo para um formato de convivência colaborativa, onde todos são ouvidos, respeitados e desenvolvem um senso de comunidade. Na prática, abre-se mão de posturas punitivas como castigos, gritos ou o famoso "cantinho do pensamento". Fica de fora também a lógica das ofertas de recompensas para obtenção da mudança de comportamento das crianças (ARIAS CHACÓN, 2018, p. 157).

Existe este preconceito e é um equívoco. Os limites são fundamentais e estruturantes para a personalidade que está se formando. Gosto de usar com os familiares a metáfora que compara os limites a uma rede de contenção para trapezistas: se a criança sabe que existem pessoas confiáveis e acolhedoras que estão prontas para mantê-las em um "lugar seguro" ao longo da vida, sem ameaçá-las, elas ficarão à vontade para experimentar sua autonomia e sentirão que existe abertura para pedir ajuda quando for necessário (NELSEN, 2015).

Um dos maiores desafios para os familiares é a disponibilidade de tempo com 
"qualidade de presença" para convivência com os filhos. A correria da rotina, as longas jornadas de trabalho, o cansaço e o tempo que dedicamos às telas em geral (celulares, televisores) são fatores que ocupam muito do espaço da convivência em família, sobrando pouca energia para as brincadeiras e o diálogo. Na prática, encontrar o caminho da gentileza e da não-violência é um desafio importante, já que, muitas pessoas passaram por processos educativos impositivos e violentos, baseados no conceito de "obediência cega". Além disso, muitas vezes os sentimentos de culpa, frustração e vergonha por sentirem-se falhando na missão de educar fazem com que os pais demorem a buscar apoio profissional, o que pode levar ao estado de exaustão e desequilíbrio de todo o sistema familiar (KOLTERMANN; PARAVENTI, 2019, p. $1-8)$.

Dicas para conseguir cooperação na disciplina positiva:

- $\quad$ Mostre empatia: seja franca e diga à criança o que você percebe que ela está sentindo e que você entende esse sentimento.

- Use exemplos pessoais para garantir essa aproximação.

- $\quad$ Encoraje: você pode auxiliar a criança a pensar em alternativas para melhorar seu desempenho na escola, por exemplo.
- Deixe a criança dar ideias. Se elas não virem espontaneamente, sugira opções para que vocês decidam juntos.

- Use a brincadeira para ensinar: a criança não come? Que tal pensar em uma brincadeira que envolva comidas, frutas e verduras? Planejar um piquenique saudável, brincar de dar comidinhas para bonecas, bichinhos de pelúcia ou dinossauros. Brincar baseando-se nas cores dos alimentos também pode ser legal. Sempre existem tarefas seguras e divertidas que podem se transformar em estímulos de contato com os alimentos (CUERVO, 2016, p. 10931110).

\section{O florescimento da disciplina positiva}

Disciplina positiva veio, primeiramente, como resposta à grandes migrações para os centros urbanos e constantes mudanças comportamentais, culturais, econômicas e políticas nas sociedades. O fato de que crianças deixaram de ser vistas como contribuintes econômicas da família e que a mulher foi deixando, pouco a pouco, o papel de exemplo de submissão, são dois fatores que fizeram com que a disciplina ficasse cada vez mais complicada de ser trabalhada, especialmente com crianças (CUERVO, 2016, p. 1093-1110). 
A disciplina positiva nasceu oficialmente no período pós-primeira Guerra Mundial, com os psiquiatras Alfred Adler e Rudolf Dreikurs. Adler realizou, ao longo dos anos, diversas pesquisas e constatou por meio de observações que a forma mais eficaz de educar crianças e jovens era através de conceitos reais de respeito, responsabilidade e resiliência (NELSEN, 2015).

Anos mais tarde, na década de 80, a Dra. Jane Nelsen e seu livro intitulado "Positive Discipline" trouxeram o assunto de volta, e, o popularizou tanto entre o meio acadêmico como entre o meio familiar.

A disciplina positiva defendida e estimulada pela Dr. ${ }^{a}$ Nelsen é moldada nos estudos dos psiquiatras Adler e Dreikurs e tem como pilar três pontos: afeto, respeito e aprendizado mútuo. Seus fundamentos são demonstrar amor aos pequenos desde os primeiros dias de vida, se impor diante deles ensinando-lhes a compreensão sobre respeito e, por fim, saber ouvir e aprender com eles sempre (ALARCÓN; CAYCHO RODRÍGUEZ, 2015, p. 59-69).

A disciplina positiva tem como base o senso do pertencimento, ou seja, fazer com que a criança se sinta conectada com o meio em que vive - seja o núcleo familiar ou escolar. É torná-la parte do todo, como membro ativo, atuante e fundamental para o desenvolvimento da comunidade em que convive (NELSEN, 2015).
Educar é uma das tarefas mais difíceis para qualquer mãe ou pai. Não importa de qual geração se faça parte ou quantos filhos se tenha, sabe-se que cada criança é um indivíduo único e singular e precisa de um olhar afetuoso, uma postura gentil e firme e uma disciplina pensada exclusivamente nela. Por isso, muitos psicólogos, pedagogos e os próprios familiares vêm, ao longo das décadas, seguindo o programa da disciplina positiva na educação de crianças e jovens (KOLTERMANN; PARAVENTI, 2019, p. $1-8)$.

Educar por meio do afeto, da representatividade e do exemplo sem perder a firmeza é andar por uma linha tênue. Apesar disso, compreender e transmitir o amor impondo limites pode resultar, a longo prazo, em cidadãos conscientes sobre suas responsabilidades e seu lugar no mundo (NELSEN, 2015).

A disciplina positiva traz uma dinâmica redonda e muito prazerosa tanto para as crianças como para os pais, pois torna cada membro da família um protagonista em potencial e reativa as relações de afeto dentro do núcleo familiar sem estresse, chantagens emocionais ou ameaças para conseguir ordem (NELSEN, 2015).

Deste modo, a disciplina positiva vem para resgatar a educação por meio do afeto, do exemplo, da compreensão e do 
respeito. É uma troca de experiência, saberes e amor, tudo pautado no respeito e no poder do pertencimento social.

\section{Implementação da disciplina positiva no cotidiano}

Disciplina positiva, na verdade, nasceu com o objetivo de ser implementada no ambiente familiar e educacional. Afinal, é dentro de casa que os pequenos aprendem as primeiras noções de disciplina e educação. É importante, antes de iniciar o processo dentro de casa, que os pais compreendam e estudem o tema com calma, façam bastante pesquisa e mantenham a mente aberta para absorver e entender de fato o que é disciplina positiva, quais seus reais impactos e como visualizar seus impactos com o passar do tempo (ALTAFIM; RODRIGUES, 2015, p. 257262) .

É necessário, também, que as famílias se conheçam muito bem, observando a personalidade de cada membro dentro do lar, a rotina do dia a dia, os gostos e interesses, tudo precisa ser planejado para que o processo de educação positiva renda bons frutos e seja confortável para todos (MARIA, 2016, p. 277).

Antes de qualquer coisa, é preciso eliminar certos vícios comportamentais que estão intrínsecos no comportamento diário sem nem ao menos o indivíduo perceber, por exemplo:
- Não ignore seu filho quando ele estiver falando: por mais ocupado ou atrasado que você esteja, pare e olhe para ele, ouça o que ele tem para dizer.

- Não barganhe ou faça chantagem: é muito comum entre os pais, para conseguir algo das crianças, que barganhe "se você comer tudo depois pode mexer no celular". NÃO FAÇA ISSO.

- $\quad$ Não faça comparações: nem entre um filho e outro e nem com outras crianças;

- $\quad$ Não grite para impor autoridade.

- Não tire do seu filho o senso de responsabilidade: seja para cuidar de um brinquedo, uma roupa, para fazer o dever de casa ou cuidar do bichinho de estimação.

Para que a disciplina positiva seja aplicada com sucesso é essencial que as famílias entendam a importância do afeto e do senso de pertencimento. Para que isso possa ser aplicado na rotina de uma casa, é essencial que os pais sigam algumas dinâmicas na hora de educar seus filhos, tais como:

- $\quad$ Reserve um tempo produtivo em família: seja para conversar sobre o dia, para ensinar uma brincadeira, para ver televisão, contar uma história, brincar etc. É necessário criar esses laços; 
- Olhe nos olhos: sempre que seu filho vier até você para perguntar algo ou contar alguma coisa, pare o que você estiver fazendo, olhe para ele e preste atenção. Olhe nos olhos do seu filho e deixe claro que você tem interesse no que ele está falando;

- Demonstre afeto: não tenha medo ou pudor em demonstrar ao seu filho o quanto você o ama e o quanto ele é importante e querido para você, faça-o se sentir querido, acolhido e amado;

- Imponha limites: dar afeto e atenção não é sinônimo de ser permissivo. Saiba impor sua presença e sua voz, criando um senso de hierarquia enquanto mantém um tom gentil e firme. Limites são essenciais para moldar a postura e o caráter de uma pessoa, mas sem gritos ou autoritarismo. Converse, explique os "nãos" e abra sempre um canal para o diálogo;

- Dê responsabilidades: dar responsabilidade desde cedo para a criança, sobre seus objetos pessoais e, principalmente, sobre suas ações, é fundamental para que ela venha a compreender a dinâmica de se viver em sociedade, sem medos e sem cobranças excessivas (MARIA, 2016, p. 277).

\section{Função da disciplina positiva dentro da educação de crianças}

A disciplina positiva é um complemento para educação de crianças. Ela vem para abrir as portas e facilitar o processo educacional, tanto no que diz respeito ao comportamento dos pequenos em sala de aula - com professores e colegas - como na dinâmica do ensino em si Nelsen (2015, p. 62).

Crianças com maior compreensão de disciplina, hierarquia e, principalmente, que entendem a importância do saber, do diálogo e do convívio harmonioso em sociedade - ainda que de forma inconsciente - aprendem melhor e mais rápido Nelsen (2015, p. 62).

Além disso, se sentir bem, respeitado e validado também é uma parte muito significativa em nosso aprendizado, evitando que certas travas sejam criadas e mantidas por longos períodos da vida (como é muito comum em crianças e jovens que passam por experiências traumáticas em âmbito escolar) (PRICINOTE, 2020, p. 1$6)$.

As escolas podem e devem usar a disciplina positiva para melhorar a troca de experiências entre alunos e professores, aplicando linguagens e exemplos que aproximem o conteúdo do aluno no dia a dia (PORTUGUESA, 2020, p. 1-21). 
É essencial que professores e pedagogos entendam que não basta apenas ensinar o que vem descrito nos livros e apostilas, é preciso conhecer o indivíduo que está ali para aprender, demonstrando interesse por ele, pela sua individualidade, pelo bem-estar de cada um e não somente com uma nota no final do semestre (DE SOUZA; BARBOSA DO NASCIMENTO; FENSTERSEIFER, 2018, p. 143-159).

A criança precisa se sentir acolhida em todos os meios que frequenta, precisa sentir-se segura, precisa confiar na figura adulta que conduz o seu caminhar, seja dentro de casa ou na escola. Toda criança deve ser tratada com afeto e cuidado, isso é fundamental para o ensino educacional. $\mathrm{O}$ professor precisa conhecer o aluno, compreender quais são suas dificuldades para poder ajudá-lo a superar um possível bloqueio da melhor maneira (MEZACASCANTE; SUÁREZ-VALDÉSAYALA; SCHMIDT-QUESADA, 2015, p. 3-24).

Acredita-se que ninguém aprende de forma igual, como em um processo de produção em massa, ou com o famoso cópia e cola. Por isso, é necessário apoia-se na disciplina positiva para moldar metodologias e formas de ensino (MINETTO; LÖHR, 2016, p. 49-64).

É necessário sempre prezar por uma metodologia participativa, onde há uma troca de saberes, de histórias e onde as portas estão sempre abertas para as novidades e para temas que são comuns e presentes na vida das crianças e jovens, como os games e redes sociais (GORBUNOVS, 2016, p. 1-6).

O ensino não pode ser uma plataforma inflexível e quadrada, feita de uma maneira que torna sua adaptação às novas gerações extremamente difícil. Pelo contrário, a educação deve ser libertadora, flexível e olhar para cada indivíduo como único. Isso facilita o aprendizado como um todo, e nos permite ensinar a cada aluno sobre superação, socialização e comprometimento

(FURGUERLE RANGEL; PACHECO BARRIOS; BASTIDAS PACHECO, 2018, p. 603$620)$.

A disciplina positiva vem ganhando força ao longo dos últimos anos, em tempos em que tecnologia avançada nos arremata a cada segundo com um mundo de informações. Ter tempo de qualidade para viver entre família se tornou essencial para muitas famílias que almejam criar seus filhos, desde os primeiros passos, para que se tornem indivíduos mais afáveis, responsáveis e conscientes sobre seu lugar na sociedade (FERREIRA; ANDRADE, 2017, p. 245-252). 


\section{CONCLUSÕES}

A Disciplina Positiva encontra alguns obstáculos no processo ensinoaprendizagem, como visto no decorrer desta pesquisa, que acabam prejudicando o exercício da função docente e o aproveitamento dos conhecimentos ministrados por parte dos alunos envolvidos. No entanto, é importante enxergar o disciplinamento como ferramenta de mudança social, isso quer dizer que o docente não deve almejar apenas a obediência do aluno, ou que sua aula flua num "mar silencioso", mediante sujeitamento da criança, mas que se importe com uma educação a longo prazo, preparando-a para lidar com os conflitos cotidianos de maneira positiva.

É comum encontrar educadores com ideias controversas no que diz respeito a rigidez/permissividade e firmeza/gentileza. De fato, a falta de crença na impossibilidade de ser firme e gentil ao mesmo tempo, convida os docentes a continuarem atuando por meio de castigos corporais e humilhantes.
Nelsen (2015, p. 62) já dizia, “Às vezes, precisamos curar a relação antes de lidar com o mau comportamento".

É verídica a necessidade de desenvolver um novo olhar sobre o mau comportamento, as crianças nem sempre conseguem usar a comunicação verbal não violenta para falar sobre o que estão sentindo, portanto, nós, educadores, precisamos estar preparados para ajudá-las a decodificar estes sentimentos. Para isso, é necessário problematizar o olhar do docente a enxergar o que não está visível. A raiva/crise pode estar disfarçada em outras questões, tais como fome, medo, necessidade de se sentir aceito no meio em que se encontra e outras infinidades de sentimentos que a subjetividade humana pode nos oferecer.

Deste modo, concluímos que o docente pode cultivar um olhar "positivo" para cada situação que venha a ocorrer em sala de aula, começando assim a desenvolver novos aprendizados a partir dos erros, sendo grato às infinitas contribuições que as crianças possam oferecer, promovendo uma educação mais respeitosa e acessível com todos os que dela usufruem.

metropolitana. Psychologia, v. 9, n. 1, p. 59-69, 2015.

ALTAFIM, E. R. P.; RODRIGUES, O. M. P. R. Maternal educational practices during the first year of life. Journal of Human 
Growth and Development, v. 25, n. 3, p. 257-262, 2015.

ARIAS CHACÓN, G. et al.

Contribuciones de la teoría disciplina positiva: Una experiencia en la comunidad rural La Maravilla, San Vito de Coto Brus. Revista Ensayos Pedagógicos, v. 13, n. 1, p. 157, 2018.

CUERVO, Á. A. V. et al. Relación entre funcionamiento familiar, emociones morales y violencia entre estudiantes de primaria. Revista Mexicana de Investigacion Educativa, v. 21, n. 71, p. 1093-1110, 2016.

\section{DE SOUZA, S. P.; BARBOSA DO NASCIMENTO, P. R.;}

FENSTERSEIFER, P. E. Atuação docente em Educação Física escolar: entre investimento e desinvestimento pedagógico. Motrivivência, v. 30, n. 54, p. 143-159, 2018.

FERREIRA, V. S.; ANDRADE, M. S. A Relação Professor-Aluno no Ensino Médio: Percepção do Professor de Escola Pública. Psicologia Escolar e Educacional, v. 21, n. 2, p. 245-252, 2017.

\section{FURGUERLE RANGEL, J.; PACHECO} BARRIOS, J.; BASTIDAS PACHECO, G. Apreciaciones sobre la quinta disciplina en la construcción de organizaciones educativas inteligentes. Actualidades Investigativas en Educación, v. 18, n. 3, p. 603-620, 2018.

GORBUNOVS, A. et al. Atuação docente em Educação Física escolar: entre investimento e desinvestimento pedagógico. Procedia - Social and Behavioral Sciences, v. 21, n. 1, p. 1-6, 2016.
KOLTERMANN, J. P.; SOUZA, C. D.; BUENO, R. K.; PARAVENTI, L.; VIEIRA, M. L. Openness to the World by Fathers and Mothers of Preschoolers in Two-parent Families. Developmental Psychology, v. 29, p. 1-8, 2019.

MARIA, A. et al. A percepção dos jovens brasileiros sobre suas aulas de Ciências. Educar em Revista, n. 60, p. 277-292, abr./jun., 2016.

MEZA-CASCANTE, L. G.; SUÁREZVALDÉS-AYALA, Z.; SCHMIDTQUESADA, S. La actitud del personal docente de matemática hacia el aprendizaje cooperativo y los elementos institucionales que favorecen o dificultan el empleo de esa metodología didáctica. Revista Electrónica Educare, v. 19, n. 1, p. 3-24, 2015.

MINETTO, M. DE F.; LÖHR, S. S. Crenças e práticas educativas de mães de crianças com desenvolvimento atípico. Educar em Revista, n. 59, p. 49-64, 2016.

NELSEN, Jane. Disciplina Positiva. 3. ed., São Paulo: Manole, 2015.

PORTUGUESA, R. Revista Portuguesa de Investigação Educacional, v. 17, p. 42-60, 2017. OLIVARES, H. et al. La urdiembre en la enseñanza: expresiones articuladoras de contenido en la interacción profesorestudiante. Educação e Pesquisa, v. 46, p. $1-21,2020$.

PRICINOTE, S. C. M. N. et al. Percepção Discente sobre o Ambiente Educacional da Disciplina de Semiologia Médica. Revista Brasileira de Educação Médica, v. 44, n. 1, p. 1-6, 2020. 